\title{
Produção da ervilha cultivada em ambiente protegido sob diferentes tensões de água no solo ${ }^{1}$
}

\author{
Jacinto de A. Carvalho², Fátima C. Rezende², Reinaldo F. Aquino², \\ Wellington A. de Freitas ${ }^{2} \&$ Eduardo C. O liveira ${ }^{2}$
}

\begin{abstract}
RESU M O
Os efeitos de diferentes tensões de água no solo aplicadas em dois estádios fenológicos da cultura da ervilha (Pisum sativum L.) foram avaliados por meio de dois experimentos, ambos conduzidos em delineamento experimental inteiramente casualizado com quatro tratamentos e quatro repetições. $\mathrm{Os}$ tratamentos se constituíram de quatro diferentes tensões de água no solo: $15,30,60$ e $120 \mathrm{kPa}$. O s resultados permitiram concluir que diferenças significativas foram encontradas para produção total da planta, número de vagens por planta e para peso médio da vagem, independentemente da fase fenológica em que foi aplicado o tratamento de tensão de água no solo; maiores quedas de produção foram observadas na fase reprodutiva, demonstrando que esta fase é mais sensível à escassez de água no solo, prejudicando o desenvolvimento da cultura; obtiveram-se maiores produções com irrigação realizada sob a tensão de $15 \mathrm{kPa}$.
\end{abstract}

Palavras-chave: manejo de irrigação, fase fenológica, produtividade, Pisum sativum L.

\section{Production of pea cultivated in protected ambient under different soil water tensions}

\begin{abstract}
Effects of different water tensions on soil applied in two phenological stages in pea (Pisum sativum L.) crop were evaluated in two experiments, both carried out in a completely randomized experimental design with four treatments and four repetitions. The treatments consisted of four different water tensions in soil: $15,30,60$ and $120 \mathrm{kPa}$. The results showed significant differences for total production of the plant, for number of beans per plant and for mean weight of the bean, independently of the phenological phase in which the treatment of tension of water was applied in the soil; larger production decrease were observed in reproductive phase, showing that this one is more sensitive to water tensions in soil; the highest production was obtained with irrigation carried out under $15 \mathrm{kPa}$ tension.
\end{abstract}

Key words: irrigation management, phenological stages, yield, Pisum sativum L. 


\section{INTRODUÇÃO}

A ervilha (Pisum sativum L.) é uma espécie anual das zonas temperadas, com crescimento determinado para cultivares destinadas à produção de grãos e indeterminado para a produção de vagens comestíveis. É considerada excelente alimento por se destacarem, em sua composição, elevados teores de proteína, vitaminas do complexo B, além de minerais como cálcio, ferro, fósforo e potássio (Pereira, 1989). Ela possui 18 a $35 \%$ de proteína, 35 a $50 \%$ de amido e 4 a $7 \%$ de fibra. $O$ teor do aminoácido lisina faz com que seja um bom complemento dos cereais, em termos nutricionais (Filgueira, 2000).

A ervilha-verde é uma opção de produção para atender às novas demandas do mercado, sobretudo de produtos supergelados. Diferente da ervilha para produção de grãos secos, os quais são posteriormente reidratados e enlatados, as cultivares de ervilha-verde são próprias para a colheita de grãos, visando ao imediato congelamento e/ou enlatamento. O produto pode também ser comercializado na forma de vagens para debulhar ou de grãos debulhados, para consumo in natura (EMBRAPA, 2008).

Em geral, a ervilha é cultivada em regiões de clima temperado, mas também pode ser explorada nos trópicos, quando a altitude compensa a latitude desfavorável. É bastante tolerante a baixas temperaturas, embora possa ser prejudicada por geadas, sobremaneira na fase de florescimento e de formação de vagens (Reis, 1989). No Brasil vem aumentando o interesse na produção da ervilha (Pisum sativum L.) cultivada sob irrigação, de maio a setembro, em sistema de cultivo múltiplo (Sharma \& Fonseca, 2000).

Em estudos de avaliação de cultivares e linhagens de ervilha realizados em Minas Gerais, as cultivares Jurema e Marina foram consideradas mais produtivas que a Mikado, pois renderam, na média de dois ensaios realizados em Uberaba e Viçosa, respectivamente 2,$13 ; 2,11 ; 2,08$ e $1,53 \mathrm{t} \mathrm{ha}^{-1}$ de grãos secos (Vieira et al., 2007).

Azevedo et al. (2002) mencionam que a região sul de Minas Gerais possui potencial de 200.000 ha de várzeas irrigáveis, que têm sido utilizadas principalmente na época das águas para o cultivo de arroz inundado. Essas áreas, devidamente drenadas e manejadas no período da seca, oferecem possibilidades de diversificação de culturas, com até duas ou mais colheitas anuais.

O cultivo de ervilha para produção de grãos secos é pouco exigente em água, pois o excesso prejudica a raiz e favorece o ataque de fungos do solo. Durante a germinação e a emergência efetuam-se irrigações leves e frequentes; a maior exigência hídrica ocorre nos estádios de florescimento e de enchimento dos grãos. No Brasil Central as irrigações são suspensas quando cerca de $50 \%$ das vagens apresentam grãos com tamanho máximo, o que ocorre por volta de 85 dias após a semeadura e, para a produção de grãos verdes, prolonga-se a irrigação até a colheita, resultando na produção de grãos mais tenros, medida que também retarda a conversão de açúcar em amido, obtendo-se ervilhas doces, que atendem à exigência do mercado para o processamento. O mesmo ocorre em culturas tutoradas para vagens comestíveis, com a manutenção da irrigação da mesma forma, inclusive ao longo do período de colheita (Filgueira, 2000).
Deste modo e a fim de suprir as necessidades hídricas das plantas de ervilha, o manejo adequado e eficiente da água no solo é indispensável no desenvolvimento vegetativo e na produtividade dos grãos desta cultura.

Na produção de hortaliças no Brasil, o cultivo em casa de vegetação tem sido muito utilizado para proteger as plantas das adversidades climáticas como, por exemplo, granizos, geadas e vento, entre outros, além de proporcionar aumento na produtividade e na qualidade de produtos. Por outro lado, a irrigação é prática obrigatória e o manejo racional da água deve ser considerado (Oliveira et al., 2011a).

A deficiência de água de irrigação é um dos fatores mais limitantes para a obtenção de elevadas produtividades, sobremaneira no cultivo de hortaliças em ambiente protegido ou em campo (Anthony \& Shingandhupe, 2004; Kirda et al., 2004; Guang-Cheng et al., 2008; Patanè \& Cosentino, 2010). Particular atenção deve ser dada ao déficit hídrico uma vez que, além de afetar significativamente a produção das culturas, sobretudo quando ocorre na fase de florescimento e, ainda, pode acarretar em decrementos no aspecto qualitativo, quando ocorre durante o período reprodutivo (Fabeiro et al., 2002; Lovelli et al., 2007; Aujla et al., 2007; Posse et al., 2009; Xiao et al., 2009). Para garantir o sucesso do cultivo nas diferentes fases das culturas, as irrigações devem ser realizadas antes que a disponibilidade de água no solo seja reduzida a níveis que alterem o metabolismo das plantas e, assim, possam comprometer a produção.

Critérios para se estabelecer o momento da irrigação podem ser baseados em função do potencial de água no solo, sendo as culturas, em geral, mais sensíveis a baixos potenciais (mais negativos) em determinados estádios de crescimento que outras. Apesar disto, poucos estudos têm sido feitos para avaliar o momento ideal de se efetuar a irrigação na cultura da ervilha, razão pela qual se objetivou, nesta pesquisa, avaliar o efeito de diferentes tensões de água no solo aplicadas em dois estádios fenológicos (vegetativo e reprodutivo) da ervilha cv. Torta de Flor Roxa, cultivada em ambiente protegido.

\section{Material E MÉTODOS}

Dois experimentos foram conduzidos em casa de vegetação no Departamento de Engenharia da Universidade Federal de Lavras, município de Lavras, MG, no período entre junho e setembro de 2008. O município está localizado na região sul do Estado de Minas Gerais, a $918 \mathrm{~m}$ de altitude, $21^{\circ} 14^{\prime}$ de Latitude Sul e $45^{\circ} 00^{\prime}$ de Longitude Oeste. Segundo a classificação de Köppen, a região apresenta um clima $\mathrm{Cwa}$, ou seja, temperado suave, chuvoso, com inverno seco, temperatura média do mês mais frio inferior a $18^{\circ} \mathrm{C}$ e superior a $3^{\circ} \mathrm{C}$ e o verão apresenta temperatura média do mês mais quente superior a $22^{\circ} \mathrm{C}$ (Dantas et al., 2007).

As condições ambientais dentro da casa de vegetação foram monitoradas diariamente através de dados de temperatura e umidade relativa do ar, com o auxílio de um termoigrômetro digital, cujas leituras eram realizadas diariamente, às $9 \mathrm{~h}$.

Utilizou-se, para ambos os experimentos, o delineamento inteiramente casualizado com quatro repetições. Os tratamentos 
compreendiam quatro níveis de tensão de água no solo $(15,30$, 60 e $120 \mathrm{kPa}$ ). No primeiro experimento (experimento I) foram avaliados os efeitos dos tratamentos aplicados durante a fase de desenvolvimento vegetativo (emergência/abertura da gema floral) sobre a produção e, no segundo experimento (experimento II) os efeitos dos tratamentos na fase reprodutiva (formação de frutos/colheita).

Cada parcela experimental foi constituída de um canteiro com dimensões de $0,3 \times 0,9 \mathrm{~m}$, com três plantas espaçadas entre si de $0,3 \mathrm{~m}$ e entre fileiras de $1,0 \mathrm{~m}$; foram plantadas três sementes da ervilha Torta de Flor Roxa diretamente no solo dos canteiros para garantir o pegamento em todos os tratamentos; após a confirmação do vigor da planta efetuouse o desbaste, deixando-se apenas uma planta. A ervilha Torta de Flor Roxa é de crescimento indeterminado, apresenta vagens de cor verde claro, comprimento entre 13 e $15 \mathrm{~cm}$, diâmetro entre 2,5 e 3,5 cm com ciclo de produção de 60 a 70 dias (Hortec, 2011).

Para o tutoramento das plantas foram utilizados mourões de madeira com 2,5 m de altura nas extremidades dos canteiros, os quais foram postos em contato através de cabos de aço que auxiliaram na colocação das fitas tipo fitilho, dispostas na vertical para que as plantas pudessem crescer atreladas a elas, de maneira a se evitar o tombamento.

O solo da área experimental foi originalmente classificado como Latossolo Vermelho Distroférrico com textura predominantemente muito argilosa. Obtiveram-se os parâmetros da equação de ajuste da curva característica de retenção de água no solo com o auxílio do software SWRC (Dourado Neto et al., 2000), que se encontram na Eq. 1:

$$
\theta=0,2350+\frac{(0,239)}{\left[1+(0,2749 \cdot|\psi|)^{2,0272}\right]^{0,5067}}
$$

em que:

$\theta \quad$ - umidade atual, $\mathrm{cm}^{3} \mathrm{~cm}^{-3}$

$\Psi$ - tensão de água no solo, $\mathrm{kPa}$

As adubações foram realizadas com base nos resultados da análise de fertilidade do solo e de acordo com as recomendações de Vieira et al. (2007) para a cultura da ervilha; na adubação de plantio foram utilizados sulfato de amônio, superfosfato simples e cloreto de potássio; as adubações de cobertura foram realizadas quinzenalmente utilizando-se nitrato de cálcio; não houve necessidade de se realizar calagem no solo da casa de vegetação.

Realizaram-se monitoramentos visuais constantes para identificação de pragas e doenças, tais como o pulgão, a ascoquitose e oídio, efetuando o controle por meio de aplicações de defensivos químicos registrados para a referida cultura, logo no surgimento dos primeiros sintomas; os controles de ervas daninhas foram realizados por meio de capina manual.

Utilizou-se um sistema de irrigação por gotejamento com emissores inseridos sobre a linha de plantio, sendo um gotejador por planta. O manejo da irrigação foi efetuado a partir da leitura média da tensão de água no solo com três tensiômetros instalados em três repetições das unidades experimentais de 15, 30 e $60 \mathrm{kPa}$; para o tratamento com tensão de $120 \mathrm{kPa}$ também se utilizaram três sensores de matriz granular Watermark ${ }^{\circledR}$ instalados em três repetições; todos os equipamentos de medição de tensão foram inseridos a $15 \mathrm{~cm}$ de profundidade no solo.

Até 10 dias após o plantio (DAP) todos os tratamentos foram irrigados igualmente, ou seja, com a mesma quantidade de água, de forma a garantir o pegamento das plântulas, procurando-se manter o solo com umidade próxima à capacidade de campo adotada $(10 \mathrm{kPa})$ período após o qual se iniciou a aplicação dos tratamentos no experimento I, referente à primeira fase fenológica (vegetativa - pós-plantio até a abertura da gema floral) até a época em que 50\% das flores das plantas se encontravam abertas; a partir deste momento os tratamentos foram suspensos e todas as unidades experimentais deste experimento passaram a ser irrigadas quando a tensão atingia $15 \mathrm{kPa}$ até a capacidade de campo; na mesma época as unidades experimentais a serem avaliadas na fase reprodutiva (experimento II) foram, então, submetidas às diferentes condições de tensão de água no solo, até o final do ciclo.

Realizou-se monitoramento da diferenciação entre os estádios fenológicos através do acompanhamento do desenvolvimento da parte aérea das plantas, contabilizando o florescimento das plantas por tratamento.

As irrigações foram realizadas quando as leituras das tensões (tensiômetros e sensores de matriz granular Watermark ${ }^{\circledR}$ ) estavam próximas do valor predeterminado para cada tratamento; os tratamentos foram irrigados até o teor de água no solo atingir a capacidade de campo (10 kPa), calculando-se o volume de reposição de água por meio da curva de retenção de água no solo, espaçamento da cultura e pela vazão dos gotejadores utilizados. A água utilizada na irrigação é proveniente de uma barragem e a condutividade elétrica e o $\mathrm{pH}$ apresentam valores médios de $0,3 \mathrm{dS} \mathrm{m}^{-1} \mathrm{e} 7,5$, respectivamente.

Foram avaliados: a produção total por planta, número de vagens por planta, número de sementes por vagem e o peso médio por vagem para as fases vegetativa e reprodutiva. As colheitas foram realizadas individualmente para cada planta. As vagens foram separadas por tratamentos e posteriormente por planta. Durante a colheita, elas eram colocadas em envelopes de papel identificados com os respectivos tratamentos e repetições e levados, posteriormente, ao laboratório de Hidráulica da Universidade Federal de Lavras, onde as vagens eram pesadas em balança de precisão e contadas quanto ao número de vagens por tratamento e quanto ao número de sementes por vagens.

Os frutos que apresentaram defeitos físicos ou fisiológicos foram classificados como refugo ou não comerciais, não sendo contabilizados. O peso médio por vagem foi obtido através da divisão do peso das vagens colhido em cada tratamento, dividido pelo número total de vagens do tratamento. O número de vagens por planta correspondeu ao número total de vagens dividido pelo número de plantas de cada tratamento.

Realizou-se análise de variância dos dados avaliados utilizando-se o teste de distribuição $\mathrm{F}$ a 1 e $5 \%$ de probabilidade; 
a comparação de médias foi analisada por meio de regressão. As análises estatísticas foram realizadas utilizando-se o software R versão 2.8.0 (R Development Core Team, 2008).

\section{RESULTADOS E DISCUSSÃO}

Durante o período de condução do experimento a temperatura média no interior da casa de vegetação foi de $20^{\circ} \mathrm{C}$ com mínima em torno de $9{ }^{\circ} \mathrm{C}$ e máxima de $32^{\circ} \mathrm{C}$. Referidos valores estão próximos à faixa ideal de temperatura para o cultivo da ervilha que, segundo Vieira et al. (2007), é de $18{ }^{\circ} \mathrm{C}$ para temperatura média, com mínima acima de $4{ }^{\circ} \mathrm{C}$ e máxima de 30 ${ }^{\circ} \mathrm{C}$. A umidade relativa média observada ao longo do experimento foi de $55,0 \%$, com máxima média de 90,8\% e mínima média de $19,2 \%$.

$\mathrm{Na}$ Tabela 1 se apresentam as épocas de início e final de cada estádio fenológico (dias após o plantio das sementes) na qual pode ser constatada praticamente a mesma duração para cada fase de desenvolvimento da cultura (vegetativa e reprodutiva).

Tabela 1. Início, final e duração das fases fenológicas da cultura da ervilha

\begin{tabular}{cccc}
\hline $\begin{array}{c}\text { Fases } \\
\text { fenológicas }\end{array}$ & $\begin{array}{c}\text { Início } \\
\text { (DAP) }\end{array}$ & $\begin{array}{c}\text { Final } \\
\text { (DAP) }\end{array}$ & $\begin{array}{c}\text { Duração } \\
\text { (dias) }\end{array}$ \\
$\begin{array}{c}\text { Vegetativa * } \\
\text { Reprodutiva ** }\end{array}$ & 10 & 47 & 37 \\
$*$ & 48 & 87 & 39 \\
\hline
\end{tabular}

* Emergência/abertura da gema floral

** Formação dos frutos/colheita

Tem-se, na Tabela 2, o resumo dos resultados da análise de variância para o experimento I (fase vegetativa - emergência/ abertura da gema floral). Verifica-se que os tratamentos adotados influenciaram significativamente na produção total por planta, número de vagens por planta e no peso médio por vagem.

Tabela 2. Resumo da análise de variância para as características produção total por planta (PTP), número de vagens por planta (N VP), peso médio por vagem (PMV) e número de sementes por vagem (NSV) para a fase vegetativa da ervilha

\begin{tabular}{lrrrrr}
\hline \multicolumn{1}{c}{$\begin{array}{c}\text { Fontes de } \\
\text { variação }\end{array}$} & G.L. & \multicolumn{4}{c}{ Quadrados médios } \\
\cline { 3 - 6 } & & PTP (g) & NVP & PMV (g) & NSV \\
Tensão (T) & 3 & $5736,16^{* *}$ & $48,52^{*}$ & $7,74^{* *}$ & 1,25 \\
Resíduo & 12 & 2046,56 & 47,84 & 4,08 & 15,94 \\
\hline C.V. (\%) & & 31,58 & 26,93 & 11,61 & 18,30 \\
\hline Média & & 72,12 & 9,41 & 7,64 & 5,85 \\
\hline
\end{tabular}

* Significativo a $5 \%$ de probabilidade

** Significativo a $1 \%$ de probabilidade

Ns Não significativo

Bilibio et al. (2010) avaliaram o efeito de diferentes tensões de água no solo aplicadas em duas fases fenológicas da berinjela cultivada em vasos em casa de vegetação, em que puderam verificar ausência de diferença estatística sobre as características avaliadas quando os tratamentos foram aplicados na fase pós-transplante/abertura da gema floral, que foi atribuído ao curto período (24 dias) em que as plantas estiveram submetidas aos tratamentos. Porém, em trabalho com pepino japonês cultivado em casa de vegetação, Oliveira et al. (2011b) verificaram que o número e a massa de frutos por planta foram significativamente influenciados pela tensão de água no solo aplicada na fase vegetativa.

Na Figura 1 são apresentadas as variações da produção total por planta (A), número de vagens por planta (B) e peso médio por vagem (C) em função da tensão de água no solo. Todas as variáveis analisadas apresentaram comportamento inversamente proporcional à tensão de água no solo. O modelo de potência descreve bem o fenômeno apresentando coeficiente de determinação $\left(R^{2}\right)$, para todas as variáveis, superior a $92 \%$. De maneira similar, Carvalhoet al. (2004) verificaram que odéficit hídrico na fase pós-transplante/abertura da gema floral promoveu redução na produção total e no número de frutos da berinjela.
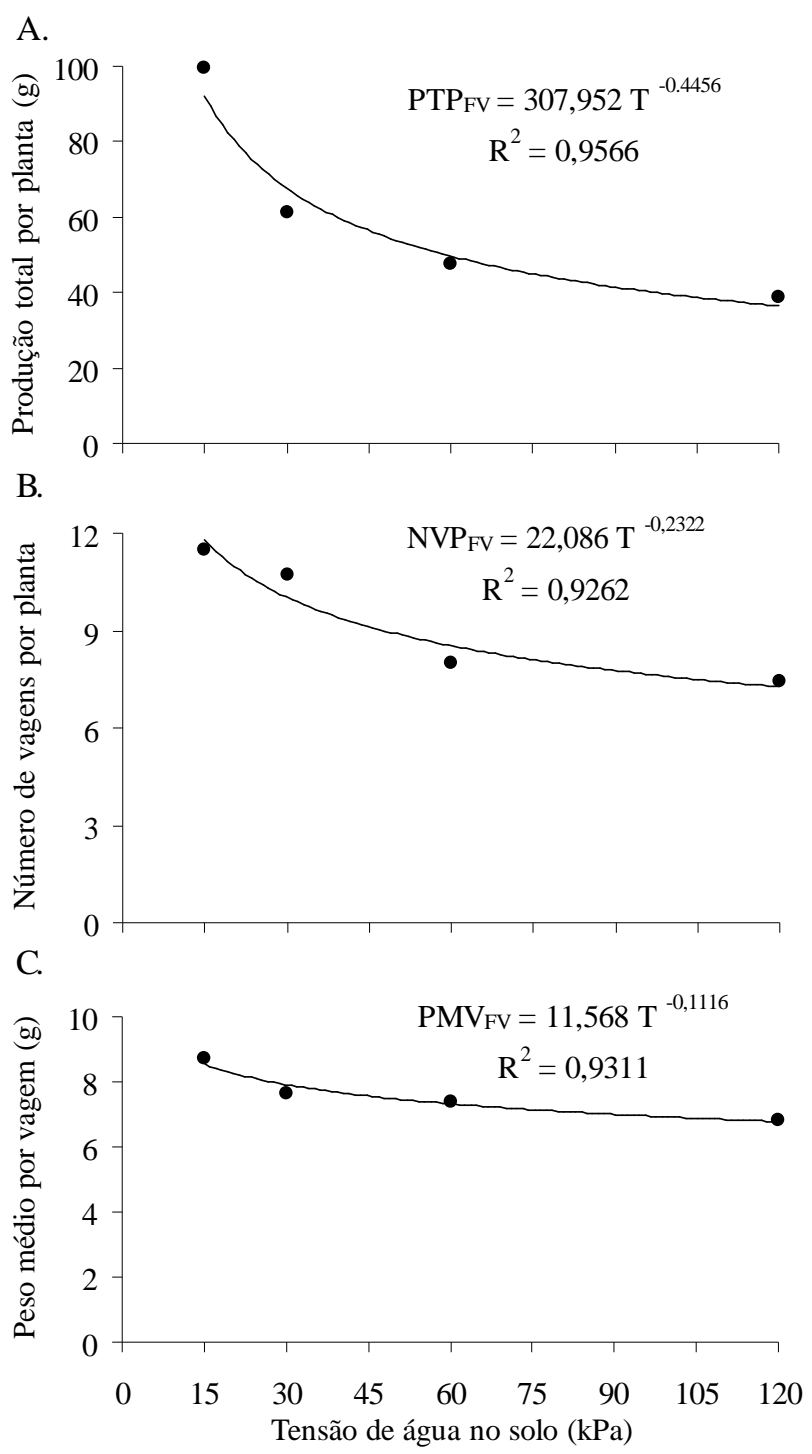

Figura 1. Produção total por planta $(A)$, número de vagens por planta $(B)$ e peso médio por vagem $(C)$ em função da tensão de água no solo na fase vegetativa da envilha 
A Tabela 3 apresenta os resultados da análise de variância para o experimento II (fase reprodutiva - formação dos frutos/ colheita). Nota-se que os tratamentos afetaram significativamente a produção total por planta, o número de vagens por planta e o peso médio das vagens. Resultados semelhantes obtiveram Oliveira et al. (2011b) trabalhando com a cultura de pepino japonês.

Tabela 3. Resumo da análise de variância para as características produção total por planta (PTP), número de vagens por planta (N VP), peso médio por vagem (PMV) e número de sementes por vagem (NSV) para a fase reprodutiva da ervilha

\begin{tabular}{lrrrrr}
\hline \multirow{2}{*}{$\begin{array}{c}\text { Fontes de } \\
\text { variação }\end{array}$} & G.L. & \multicolumn{4}{c}{ Quadrados médios } \\
\cline { 3 - 6 } & & PTP (g) & NVP & PMV (g) & NSV \\
Tensão (T) & 3 & $7472,66^{* *}$ & $77,47^{*}$ & $5,43^{* *}$ & $0,95^{\text {NS }}$ \\
Resíduo & 12 & 5468,23 & 81,88 & 2,88 & 6,79 \\
\hline C.V. (\%) & & 43,36 & 37,08 & 9,90 & 12,15 \\
\hline Média & & 67,74 & 8,79 & 7,52 & 5,91 \\
\hline
\end{tabular}

* Significativo a $5 \%$ de probabilidade;

** Significativo a $1 \%$ de probabilidade

Ns Não significativo

Na Figura 2 são apresentadas as variações da produção total por planta (A), número de vagens por planta (B) e peso médio por vagem (C) em função da tensão de água no solo na fase reprodutiva. Verifica-se que todas as variáveis analisadas foram reduzidas com o aumento da tensão da água no solo, o que pode ser explicado através de modelos matemáticos da forma potencial, com bom coeficiente de determinação $\left(\mathrm{R}^{2}>\right.$ $89 \%$ ). Esses resultados demonstram que as características produtivas da cultura são favorecidas quando o solo é mantido com umidade próxima à capacidade de campo. Marouelli et al. (2002) verificaram, trabalhando com uma cultivar de alho, que o maior desenvolvimento vegetativo, a produtividade total e a massa média de bulbos foram obtidos com tensões de água no solo de 15 a $19 \mathrm{kPa}$. Resultados apresentados por Bilibio et al. (2010) com a cultura de berinjela indicaram que a maior produtividade foi obtida quando a irrigação, na fase reprodutiva, foi realizada quando a tensão da água no solo atingia $15 \mathrm{kPa}$.

Considerando a tensão de $15 \mathrm{kPa}$ como referencial, ou seja, a tensão aplicada que obteve a maior produção total por planta, número de vagens por planta e peso médio por vagem, atribuiuse o percentual de redução para cada variável analisada e, na Tabela 4, indica-se a queda relativa de produção média em função da tensão de água no solo, nas duas fases fenológicas. Observa-se que a fase reprodutiva é, de forma geral, mais sensível ao déficit hídrico quando comparada à fase vegetativa para os mesmos valores de tensão de água no solo. Desta maneira, pode-se inferir que a cultura da ervilha se mostra bastante sensível ao déficit hídrico, notadamente quando a tensão definida para irrigação passa de 15 para $30 \mathrm{kPa}$, apresentando um valor de queda de produção de 38,50 e 43,04\%, aplicada na fase vegetativa e reprodutiva, respectivamente. Segundo Marouelli \& Silva (2006), a tensão matricial crítica que maximizou a produtividade do tomateiro para processamento durante o estádio de frutificação, foi de $10 \mathrm{kPa}$.
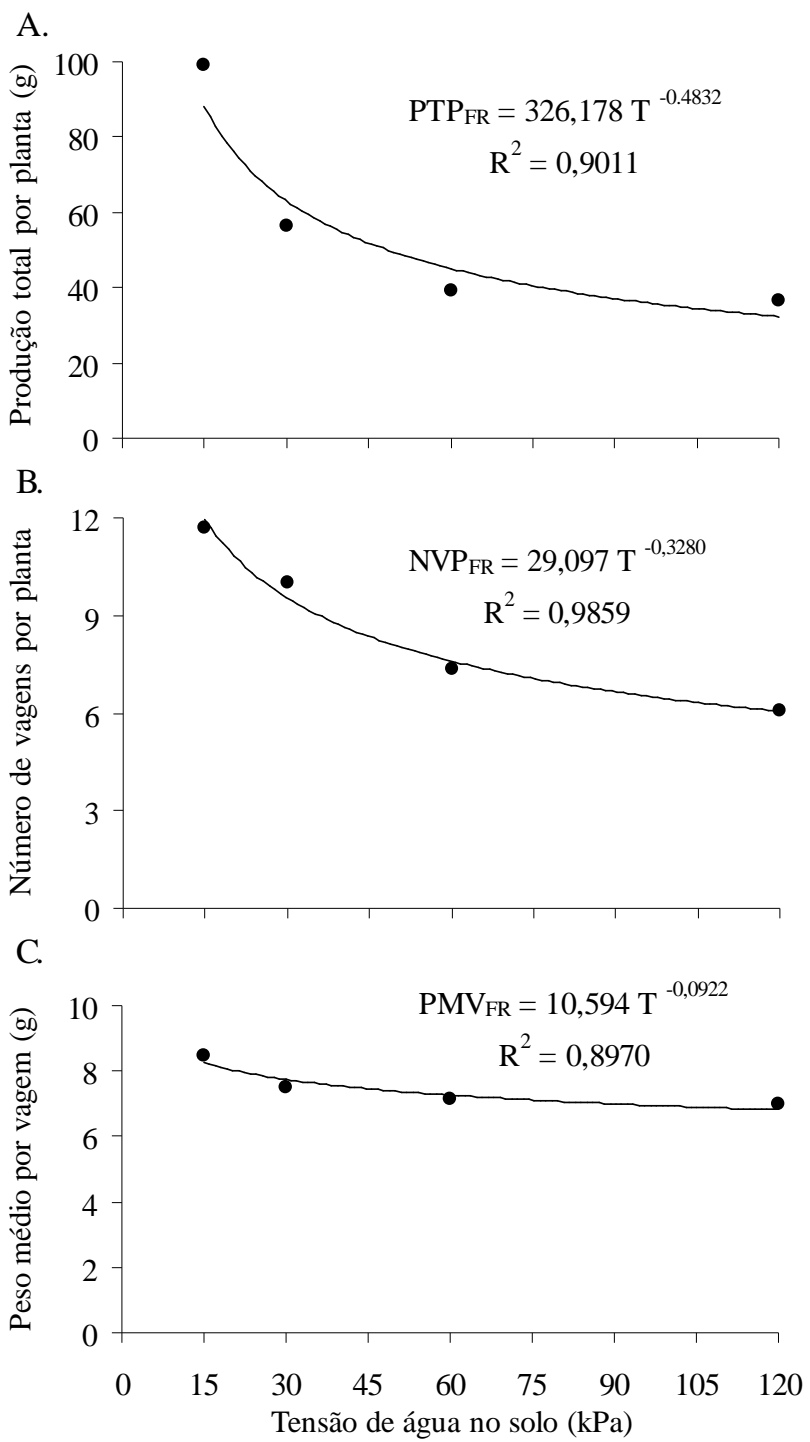

Figura 2. Produção total por planta $(A)$, número de vagens por planta $(B)$ e peso médio por vagem $(C)$ em função da tensão de água no solo na fase reprodutiva da envilha

Os dados mostrados nas Figuras 1 e 2 e na Tabela 4 demonstram que o déficit hídrico pode promover redução no desenvolvimento vegetativo e, consequentemente, na produtividade da cultura, uma vez que a restrição hídrica pode reduzir a absorção de nutrientes e induzir o fechamento dos estômatos para reduzir a transpiração. O fechamento dos estômatos dificulta a absorção de dióxido de carbono que é

Tabela 4. Q ueda relativa da produção total por planta (PTP), número de vagens por planta (N VP) e do peso médio por vagem (PMV) em função da tensão de água no solo para as fases vegetativa (V) e reprodutiva (R)

\begin{tabular}{|c|c|c|c|c|c|c|}
\hline \multirow{2}{*}{$\begin{array}{l}\text { Tensão } \\
\text { (kPa) }\end{array}$} & \multicolumn{2}{|c|}{ PTP (\%) } & \multicolumn{2}{|c|}{ NVP (\%) } & \multicolumn{2}{|c|}{ PMV (\%) } \\
\hline & V & $\mathbf{R}$ & V & $\mathbf{R}$ & V & $\mathbf{R}$ \\
\hline 15 & 0,00 & 0,00 & 0,00 & 0,00 & 0,00 & 0,00 \\
\hline 30 & 38,50 & 43,04 & 6,59 & 14,54 & 12,73 & 11,12 \\
\hline 60 & 52,37 & 60,41 & 30,62 & 37,01 & 15,19 & 15,87 \\
\hline 120 & 61,11 & 63,03 & 35,43 & 48,11 & 21,99 & 17,70 \\
\hline
\end{tabular}


fixado pelas reações de fotossíntese, formando os carboidratos e que a redução na atividade de assimilação de carbono pode reduzir o desenvolvimento e a produtividade da cultura.

De acordo com os resultados obtidos neste trabalho, para se obter níveis elevados de produtividade, a irrigação da cultura de ervilha deve ser realizada com tensão de água no solo máxima de $15 \mathrm{kPa}$. Resultados semelhantes foram encontrados por Santana et al. (2004), Halfeld-Vieira et al. (2005) e Gadissa \& Chemeda (2009), trabalhando com pimentão; Sá et al. (2005) em trabalho com tomate; Bilibio et al. (2010) para a cultura da berinjela, Pereira et al. (2009) na cultura do gladíolo e Oliveira et al. (2011b) com a cultura de pepino japonês.

Maiores tensões de água no solo representam déficit hídrico para as culturas. Deste modo, Duzdemir et al. (2009) observaram que a ervilha submetida ao estresse hídrico apresenta perdas no rendimento da cultura. Endres et al. (2010) e Santana et al. (2008) notaram que o déficit hídrico aplicado para a cultura do feijão acarretou sensível redução da produtividade.

\section{CONClusões}

1. A produção total por planta, o número de vagens por planta e o peso médio por vagem da cultura da ervilha, apresentaram redução com o incremento da tensão de água no solo, sendo mais evidenciada na fase reprodutiva.

2. Melhores produções foram observadas nos tratamentos irrigados com a tensão de água no solo de $15 \mathrm{kPa}$, independentemente da fase fenológica.

\section{AgRADECIMENTOS}

Ao Conselho Nacional de Desenvolvimento Científico e Tecnológico $(\mathrm{CNPq})$ pelo financiamento do projeto.

\section{LITERATURA CITADA}

Anthony, E.; Shingandhupe, R. B. Impact of drip and surface irrigation on growth, yield and WUE of capsicum (Capsicum annuит L.). Agricultural Water Management, v.65, p.121$132,2004$.

Aujla, M. S.; Thind, H. S.; Buttar, G. S. Fruit Yield and water use efficiency of eggplant (Solanum melongena L.) as influenced by different quantities of nitrogen and water applied through drip and furrow irrigation. Scientia Horticulturae, v.112, p.142148, 2007.

Azevedo, W. R. de; Faquin, V.; Moreira, F. M. de S.; Oliveira Júnior, A. C. de; Lisboa, C. C. Efeito do boro na nodulação da ervilha cultivada em solos de várzea. Pesquisa Agropecuária Brasileira, v.37, p.1137-1143, 2002.

Bilibio, C.; Carvalho, J. A.; Martins, M. A.; Rezende, F. C.; Freitas, E. A.; Gomes, L. A. A. Desenvolvimento vegetativo e produtivo da berinjela submetida a diferentes tensões de água no solo. Revista Brasileira de Engenharia Agrícola e Ambiental, v.14, p.730-735, 2010.
Carvalho. J. de A.; Santana, M. J. de; Pereira, G. M.; Pereira, J. R. D.; Queiroz, T. M. Níveis de déficit hídrico em diferents estágios fenológicos da cultura de berinjela (Solanum melongena L.). Engenharia Agrícola, v.24, p.320-327, 2004.

Dantas, A. A. A.; Carvalho, L. G.; Ferreira, E. Classificação e tendências climáticas em Lavras, MG. Ciência e Agrotecnologia, v.31, p.1862-1866, 2007.

Dourado Neto, D.; Nielsen, D. R.; Hopmans, J. W.; Reichardt, K.; Bacchi, O. O. S. Software to model soil water retention curves (SWRC, version 3,00). Scientia Agricola, v.57, p.191192,2000

Duzdemir, O.; Kurunc, A.; Unlukara, A. Response of pea (Pisum sativum) to salinity and irrigation water regime. Bulgarian Journal of Agricultural Science, v.15, p.400-409, 2009.

EMBRAPA - Empresa Brasileira de Pesquisa Agropecuária. Centro Nacional de Pesquisa de Hortaliças. Ervilha para produção de grãos verdes. www.cnph.embrapa.br/ cultivares/ervilha. 30 Nov. 2008.

Endres, L.; Souza, J. L. de; Teodoro, I.; Marroquim, P. M. G.; Santos, C. M. dos; Brito, J. E. D. de. Gas exchange alteration caused by water deficit during the bean reproductive stage. Revista Brasileira de Engenharia Agrícola e Ambiental, v.14, p.11-16, 2010.

Fabeiro, C.; Olalla, F. M. S.; Juan, J. A. Production of muskmelon (Cucumis melo L.) under controlled deficit irrigation in a semi-arid climate. Agricultural Water Management, v.54, p.93-105, 2002.

Filgueira, F. A. R. Novo manual de olericultura: Agrotecnologia moderna na produção e comercialização de hortaliças, Viçosa: UFV, 2000. 402p.

Gadissa, T.; Chemeda, D. Effects of drip irrigation levels and planting methods in yield and yields components of green pepper (Capsicum annuum L.) in Bako, Ethiopia. Agricultural Water Management, v.96, p.1173-1178, 2009.

Guang-Cheng, S.; Yu, Z. Z.; Na, L.; Shuang-En. Y.; Xeng-Gang, $\mathrm{X}$. Comparative effects of deficit irrigation (DI) and partial rootzone drying (PRD) on soil water distribution, water use, growth and yield in greenhouse grown hot pepper. Scientiae Horticulturae, v.119, p.11-16, 2008.

Halfeld-Vieira, B. A.; Nechet, K. L.; Pereira, P. R. V. S.; Mourão Júnior, M. Aspectos Agronômicos de Híbridos de Pimentão em Cultivo Protegido de Roraima. Boa Vista: Embrapa Roraima, 2005. 15p. Boletim de Pesquisa, 1

Hortec - Hortec Tecnologia de Sementes. <http:// www.hortec.com.br/ervilha-roxa1.htm>. 18 Out. 2011.

Kirda, C.; Cetin, M.; Dasgan, Y.; Topcu, S.; Kaman, H.; Ekici, B.; Derici, M. R.; Ozguven, A. I. Yield response of greenhouse grown tomato to partial root drying and conventional deficit irrigation. Agricultural Water Management, v.69, p.191-201, 2004.

Lovelli, S.; Perniolla, M.; Ferrara, A.; Tommaso, T. D. I. Yield response factor to water (ky) and water use efficiency for Carthamus tinctorius L. and Solanum melongena L. Agricultural Water Management, v.92, p.73-80, 2007.

Marouelli, W. A.; Silva, W. L. C. Irrigação por gotejamento do tomateiro industrial durante o estádio de frutificação, na região de Cerrado. Horticultura Brasileira, v.24, p.342-346, 2006. 
Marouelli, W. A.; Silva, W. L. C.; Carrijo, O. A.; Silva, H. R. Produção e qualidade de alho sob regimes de água no solo e doses de nitrogênio. Horticultura Brasileira, v.20, p.191194, 2002.

Oliveira, E. C.; Carvalho, J. A.; Rezende, F. C.; Freitas, W. A. Viabilidade técnica e econômica da produção de ervilha (Pisum sativum L.) cultivada sob diferentes lâminas de irrigação. Engenharia Agrícola, v.31, p.324-333, 2011a.

Oliveira, E. C.; Carvalho, J. A.; Silva, W. G.; Rezende, F. C.; Almeida, W. F. Effects of water deficit in two phenological stages on production of japanese cucumber cultived in greenhouse. Engenharia Agrícola, v.31, p.676-686, 2011 b.

Patanè, C.; Cosentino, S. L. Effects of soil water deficit on yield and quality of processing tomato under a Mediterranean climate. Agricultural Water Management, v.97, p.131-138, 2010.

Pereira, A. S. Ervilha: Integração pesquisa / Iniciativa Privada. Informe Agropecuário, v.14, p.52-64, 1989.

Pereira, J. R. D.; Carvalho, J. A.; Paiva, P. D. O.; Silva, D. J.; Sousa, A. M. G.; Souza, K. J. Crescimento e produção de hastes florais de gladíolo cultivado sob diferentes tensões de água no solo. Ciência e Agrotecnologia, v.33, p.965-970, 2009.

Posse, R. P.; Bernardo, S.; Sousa, E. F.; Messias, G. P.; Monerat, P. H.; Gottardo, R. D. Relação entre a produtividade do mamoeiro e o déficit hídrico (ky) na região Norte Fluminense. Revista Brasileira de Engenharia Agrícola e Ambiental, v.13, p.158-164, 2009.
R Development Core Team. R: A language and environment for statistical computing: reference index version 2.8.0. Vienna Foundation for Statistical Computing, 2008. Disponível em: <http://www.r-project.org.> 11 Jan. 2008

Reis, N. V. B. dos. O clima e a cultura da ervilha. Informe Agropecuário, v.14, p.8-9, 1989.

Sá, N. S.; Pereira, G. M.; Alvarenga, M. A. R.; Mattioli, W.; Carvalho, J. A. Comportamento da cultura do tomateiro sob diferentes tensões de água no solo em ambiente protegido. Revista Brasileira de Engenharia Agrícola e Ambiental, v.9, p.341-347, 2005.

Santana, M. J. de; Carvalho, J. de A.; Andrade, M. J. B. de; Braga, J. C.; Gervásio, G. G. Coeficiente de cultura e análise do rendimento do feijoeiro sob regime de irrigação. Irriga, v.13, p.92-112, 2008.

Santana, M. J. de; Carvalho, J. de A.; Faquin, V.; Queiroz, T. M. de. Produção do pimentão (Capsicum annuum L.) irrigado sob diferentes tensões de água no solo e doses de cálcio. Ciência e Agrotecnologia, v.28, p.1385-1391, 2004.

Sharma, R. D.; Fonseca, C. E. L. Efeito de meloidogyne javanica no crescimento da ervilha. Pesquisa Agropecuária Brasileira, v.5, p.115-120, 2000.

Vieira, R. F.; Pinto, C. M. F.; Vieira, C. E. In: 101 culturas: manual de tecnologia agrícola. Paula Júnior, T. J. de. Venzon, M. Belo Horizonte: EPAMIG, 2007. 800p.

Xiao, G.; Zhang, Q.; Wang, R.; Yao, Y.; Zhao, H.; Bai, H.; Xiong, Y. Effects of temperature increase on pea production in a semiarid region of China. Air, Soil and Water Research, v.2, p.31-39, 2009. 